\section{Biology of the intertidal zone}

Biology of Intertidal Animals. By R. C. Newell. Third edition. Pp. 781. (Marine Ecological Surveys: Faversham, UK, 1979.) $£ 22$.

Ir is almost ten years since the first edition of Professor Newell's book appeared, and during those ten years there has been a revolution in the approach to the study of intertidal animals. Much of the natural history, the ways of life and overall ecology of the commoner intertidal animals was familiar and ably put together in the first edition. What has happened since is a reappraisal of intertidal invertebrate biology by zoologists interested in the physiological and biochemical strategies used by animals in adaptation to their particular niches. Fields of particular interest which may be mentioned are those of temperature acclimation, energy budgets and facultive anaerobiosis. This new edition contains much of the original descriptions of the basic natural history, feeding mechanisms, and so on. Although these parts are brought up to date, the arrangement of the chapters is different and reflects this change in emphasis which has occurred within the last few years.

The book is cast in four sections: distribution patterns, energy acquisition, metabolic energy expenditure, and a final chapter on energy budgets. Thus, although the first edition ended with a chapter on thermal stress and desiccation, the tolerance of environmental stresses generally is brought forward and the subject is properly discussed after the initial descriptions of the intertidal environment. This includes the recent work by Trueman and coworkers on burrowing. The descriptions of faunas of special habitats has been updated by the inclusion of the discussion of the work of Fenchel, Wieser and others on the role of bacteria and other microorganisms in the ecology of fine deposits. The chapter which follows integrates the many diverse factors influencing the distribution of intertidal organisms, emphasising the fact that the distribution and occurrence of any species is the resultant of the interplay of many factors. There is a useful introduction to Alderdice's approach to this problem illustrated by various examples, including Professor Newell's own recent work on Ligia. In the energy acquisition section there are useful discussions of the roles of dissolved nutrients, of microorganisms in the energy equations, and of deposit and filter feeding, and it is indicative of the modern approach that these discussions precede the description of the actual feeding mechanisms. The concept of ration and factors affecting feeding rate and the energy budgets are properly discussed after the updated descriptions of feeding.

The third section concerns energy expenditure indicated by respiratory rate and includes discussions of the interesting work of de Zwaan, Bayne, Hockachka and others on facultative anaerobiosis and of the factors affecting the rate of oxygen uptake in aerobic conditions. The final chapter attempts an integration of the various adjustments available to organisms to maintain optimal fitness.

Review papers and some recent books concerned with thermal acclimation, anaerobic pathways, enzyme biochemistry and multi-factorial analy-

\section{Rock \\ mechanics}

Experimental Rock Deformation: The Brittle Field. By M. S. Paterson. Pp. 254. (Springer: Berlin, Heidelberg and New York, 1978.) DM48; \$24.

LABORATORY experiments aimed at defining the mechanical characteristics of rocks under high confining pressure constitute a growth industry; people concerned with tectonic processes, earthquakes or the proper design of foundations for civil engineering projects are the customers. The subject divides naturally into the study of plastic deformation and the study of brittle fracture: the monograph under review is largely concerned with the second, but in spite of its title, it incorporates a valuable chapter on the brittleductile transition in rocks.

Professor Paterson, who has built up a flourishing school of rock mechanics in Canberra, has successfully set out to assemble a concise source-book. The bibliography is very extensive indeed and a scan through dates shows how modern a subject this is. David Griggs in California, building on the experimental genius of Percy Bridgman, was the father of modern rock mechanics, and his first citation dates back only to 1935 . This bibliography will be of lasting value.

There are major differences between the mechanical behaviour of rocks and of metals, even brittle metals. Professor Paterson shows an impressive familiarity with the metallurgical literature and refers to it whenever it can illuminate a matter in hand; a special appendix is devoted to modern fracture mechanics, the metallurgists' creation. One special feature of rock behaviour sis are not easy reading even for most advanced undergraduates. Where Professor Newell deserves congratulation in his new edition is in not only providing excellent summaries in themselves but in giving sufficient background for students for an appreciation of these exciting fields of research as an introduction for their further study. The book is very well produced in a larger format than the original and is to be recommended to all who wish to understand the biology of the intertidal zone. No library serving students' needs in the biological sciences should be without it.

R. P. Dales

R. P. Dales is Professor of Zoology at Bedford College, University of London, UK.

which is very clearly set out here is the linkage between incipient fracture and an anomalous enhanced dilatancy, an increase in specific volume. In the brittle-ductile transition, dilatancy again plays a major diagnostic role, and a distinction can be made between cataclastic flow (the microf racturing of rock followed by relative displacement of the fragments) and true crystal plasticity. The former process, but not the latter, is associated with measurable dilatancy. It seems that the dilatancy here discussed is much larger than the uniaxial micnostrain preceding yield long studied by metallurgists.

Another unfamiliar subject well explained in the book is the stick-slip mechanism of frictional displacement, which has numerous implications for the behaviour of rock, both macroscopic and microscopic; presumably it serves to define the conditions of cataclastic flow. This chapter nicely supplements the long familiar treatment by Bowden and Tabor (The Friction and Lubrication of Solids; Clarendon/ Oxford University Press: Oxford, 1950, 1964), who largely concern themselves with metallic friction. In this chapter and elsewhere in the book, Professor Paterson shows a necessary concern with the characteristics of the testing machine, stiffness in particular, which have a marked effect on the apparent fracture or flow behaviour of rock samples.

The book is exceptionally good value for money, and the reviewer now looks forward to completing his set in a few years' time with a companion volume on the plastic deformation of rocks.

R. W. Cahn

R. W. Cahn is Professor of Materials Science at the University of Sussex, Brighton, UK. 